\title{
Pediatric Traumatic Brain Injury Pattern at the General Hospital, Douala, Cameroon
}

\author{
Aurélien Ndoumbe ${ }^{1 *}$, Mathieu Motah1, Angéline Rolande Assomo Dah', Mireille Moumi² \\ ${ }^{1}$ Faculty of Medicine \& Pharmaceutical Sciences, University of Douala, Douala, Cameroon \\ ${ }^{2}$ Neurosurgeon, Service of Surgery, General Hospital of Douala, Douala, Cameroon \\ Email: *aurelien.ndoumbe@gmail.com, *aurelen@yahoo.fr
}

How to cite this paper: Ndoumbe, A., Motah, M., Dah, A.R.A. and Moumi, M. (2019) Pediatric Traumatic Brain Injury Pattern at the General Hospital, Douala, Cameroon. Open Journal of Modern Neurosurgery, 9, 49-60. https://doi.org/10.4236/ojmn.2019.91007

Received: November 16, 2018

Accepted: January 18, 2019

Published: January 21, 2019

Copyright $\odot 2019$ by author(s) and Scientific Research Publishing Inc. This work is licensed under the Creative Commons Attribution International License (CC BY 4.0).

http://creativecommons.org/licenses/by/4.0/

\section{c) (i) Open Access}

\begin{abstract}
Traumatic brain injury is the most common injury during childhood comprising $60 \%$ to $90 \%$ injuries in children. Pediatric traumatic brain injury has peculiarities as compared to adults, such as less severe injuries and better prognosis. The purpose of this work was to study the pattern of pediatric traumatic brain injury at the General Hospital, Douala, Cameroon. This was a retrospective cross-sectional study, from January 1st, 2008 to December 31st, 2017. Included were all complete medical records of children aged 0 to 15 years old treated for traumatic brain injury, and excluded records of obstetric trauma. Data analysis was done by SPSS software version 18.0. One hundred and three cases of pediatric head injuries were recorded during the study period (frequency $10.43 \%$ ). The mean age was $7.42 \pm 5.028$ years, and the sex ratio was 2.67 in favor of boys. Road traffic accidents were the most common etiology (44.7\%). $83.5 \%$ of the patients were transferred to the emergency department of the Douala General Hospital in second intention and by non-medical transport. The traumatic brain injury was mild in $61.20 \%$. The brain computed tomography scan was performed in $99 \%$ of the cases and the most observed lesion was cerebral edema (32.74\%). Twenty-eight patients underwent surgical operation. $90.28 \%$ of patients have recovered fully, and the global mortality was $3.88 \%$. The prevalence of pediatric traumatic brain injuries at the General Hospital, Douala during the last ten years was $10.43 \%$. Most of the patients recovered fully and the mortality was low.
\end{abstract}

\section{Keywords}

Traumatic Brain Injury, Pediatrics, Computed Tomography Scanning, Treatment, Outcome

\section{Introduction}

Traumatic brain injury (TBI) can be defined as an alteration in brain function 
resulting from blunt or penetrating force to the head or as a non-congenital assault to the brain caused by mechanical energy to the head from external forces [1] [2] [3]. Pediatric TBI (PTBI) is TBI affecting children. TBI can be classified into mild, moderate or severe (Table 1) [4]. There is terminological confusion regarding TBI and specifically mild TBI which has received many definitions from different authorities. The WHO defines mild TBI as acute brain injury resulting from mechanical energy to the brain from external physical forces and which includes one or more of the following: confusion or disorientation; loss of consciousness 30 minutes; post-traumatic amnesia < 24 hours; transient neurological abnormalities, such as focal signs, seizure, intracranial lesion not requiring surgery (GCS 13 - 15 after 30 minutes) [5].

The child's head anatomy and physiology differ from that of the adult: the head to body ratio is greater; skull bones are thinner, elastic and deformable; the brain is less or not fully developed; brain swelling is more frequent and hypovolemic shock can occur from blood loss due to scalp bleeding. Globally, the outcome of pediatric TBI is better compared to adults. Traumatic brain injuries (TBI) are the most frequent injuries during childhood, recorded in $60 \%$ to $90 \%$ of children with trauma, and TBI is the leading cause of death and disability in children. Hopefully, they are mild in $80 \%$ to $90 \%$ of the cases [5]. In the USA, pediatric TBI (PTBI) has an annual incidence estimate of 180 cases per 100,000 and is responsible for 2 million emergency department (ED) visits each year, which is underestimated, because not all TBI are present to ED. Also in the USA, PTBI cause 60,000 hospitalizations, 7400 deaths annually, and 125,000 children are living with TBI related disability. Severe PTBI have 20\% mortality, 50\% unfavorable outcome at six months, and overall life costs are estimated at 60.4 \$billions [2] [4]-[11]. In Cameroon, few studies have been done on PTBI. Ndoumbé et al. have found a prevalence of $14.81 \%$ of PTBI in severe TBI patients admitted at the surgical intensive care unit of the University Teaching Hospital, Yaoundé, between January 2011 and December 2016 [12].

The most frequent modes of injury for PTBI are falls and road traffic accidents (RTA). Most of the studies report a male predominance with no difference concerning the outcome. The diagnosis imaging modality of choice is non-enhanced computed tomography (CT) scanning of the head [6] [8] [9] [13]-[18].

The management of PTBI is still debated, especially for mild and moderate TBI. For severe PTBI, the controversy is less sharp and its management includes the prescription of CT scan of the head, admission to ICU, intubation and

Table 1. Classification of traumatic brain injury [4].

\begin{tabular}{cccc}
\hline Classification & GCS & Loss of consciousness & Post-traumatic amnesia \\
\hline Mild & $13-15$ & $0-30$ minutes & $<1$ day \\
Moderate & $9-12$ & 30 minutes -24 hours & $1-7$ days \\
Severe & $3-8$ & $>24$ hours & $>7$ days
\end{tabular}

GCS: Glasgow coma scale. Severity of TBI is classified based on the highest severity in any column. 
mechanical ventilation, at a level I (pediatric) trauma center (having permanent neurosurgical team) [4] [16].

Because of the aforementioned reasons, this study was conducted in order to have a better understanding and to improve the management of PTBI at our institution.

\section{Patients and Methods}

It was cross-sectional retrospective analysis of 103 cases of PTBI managed at the General Hospital, Douala, (GHD) Cameroon, from the $1^{\text {st }}$ January 2008 to December $31^{\text {st }} 2017$. The GHD is a tertiary referral hospital with a level I trauma center comprising 3 full-time neurosurgeons with emergency (pediatric and adult), pediatric, surgical and resuscitation departments amongst other. It has a multiple barrettes CT scanner and a 0.4 tesla MRI (Toshiba, Tokyo, Japan). The study was granted ethical committee agreement and informed consent was obtained from patients 'parents and confidentiality of the data gathered was respected. The study involved the medical records of all consecutive cases of PTBI. The inclusion criteria were as follows: patients aged zero to 15 years; all genders; definite diagnosis of TBI associated or not with extra cranial injury; complete medical records. The criteria for non-inclusion were as follows: obstetrical trauma, incomplete files, patients older than 15 years, non-head trauma patients. The sampling method was non-probabilistic consecutive recruitment.

The data concerning age, gender, mode of injury, past medical history, transportation means, complaints, physical examination findings, CT findings, management procedures and the outcome were gathered. The severity of the TBI was determined by the GCS score or the pediatric GCS for patients under 4 years of age (Table 2). The TBI was labeled mild TBI for GCS score between 13 and 15, moderate PTBI for GCS score of 9 to 12, and severe PTBI if the GCS score was $\leq 8$. The statistical analysis was done with the software SPSS version 18.0 (Microsoft, Seattle, USA).

\section{Results}

\subsection{Socio Demographic Data}

During the study period, 987 cases of TBI were admitted at the emergency department of GHD, 103 cases were children giving a prevalence of $10.43 \%$ for PTBI. The PTBI patients comprised 75 boys and 28 girls, sex ratio, 2.67. Figure 1 gives the age distribution of the patients. The mean age was $7.42 \pm 5.028$ years (median, 6 years, and range, 1 to 15 years).

\subsection{Clinical Data}

Table 3 summarizes the general features of the study population. The first mode of injury was the RTA in $44.66 \%$ of the cases. The transport from injury site to the hospital was done by non-medical means in most cases. The loss of consciousness at the time of injury was the most frequent clinical manifestation 
Distribution of children according to age

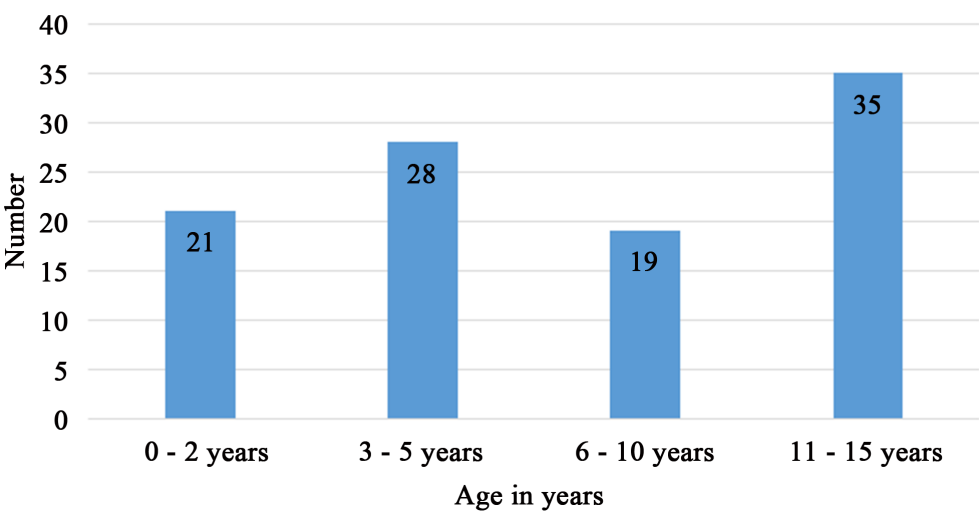

Figure 1. Distribution of patients according to age. Mean age: $07.42 \pm 05.028$ years. Median, six years. Range, 01 to 15 years. Children between 11 and 15 years of age were the most numerous.

Table 2. The pediatric Glasgow coma scale (GCS).

\begin{tabular}{|c|c|c|c|}
\hline \multicolumn{4}{|c|}{ Eyes opening } \\
\hline Score & Age $<1$ year & Age $>1$ year & \\
\hline 4 & Opens eyes spontaneously & Opens eyes spontaneously & \\
\hline 3 & Opens to shout & Opens to verbal command & \\
\hline 2 & Opens to pain & Opens to pain & \\
\hline 1 & No eye opening & No eye opening & \\
\hline \multicolumn{4}{|c|}{ Motor response } \\
\hline Score & Age $<1$ year & Age $>1$ year & \\
\hline 6 & Normal movements & Obeys verbal commands & \\
\hline 5 & Localizes to noxious stimuli & Localizes to noxious stimuli & \\
\hline 4 & Flexion withdrawal & Flexion withdrawal & \\
\hline 3 & Flexion/Decorticate posturing & Flexion/Decorticate posturing & \\
\hline 2 & Extension/Decerebrate posturing & $\begin{array}{c}\text { Extension/Decerebrate } \\
\text { posturing }\end{array}$ & \\
\hline 1 & No response to noxious stimuli & No response to noxious stimuli & \\
\hline \multicolumn{4}{|c|}{ Verbal response } \\
\hline Score & $0-23$ months old & 2 - 5 years old & $>5$ years old \\
\hline 5 & Smiles/coos/cries appropriately & $\begin{array}{c}\text { Appropriate } \\
\text { words or phrases }\end{array}$ & $\begin{array}{c}\text { Orientated } \\
\text { (normal conversation) }\end{array}$ \\
\hline 4 & Cries/consolable crying/screams & Inappropriate words & Confused $^{\S}$ \\
\hline 3 & Irritable/inconsolable & Cries/screams & Inappropriate $^{*}$ \\
\hline 2 & Grunts/agitated & Grunts & Incomprehensible ${ }^{\#}$ \\
\hline 1 & None & None & None \\
\hline
\end{tabular}

To obtain the GCS score, eye opening, verbal and motor responses points are added to each other. Minimum $=3$; maximum $=15 .{ }^{\varsigma}:$ conversation is possible, but signs of mental confusion are noticed. ${ }^{*}$ : comprehensible words, but conversation is not possible. ${ }^{*}$ : incomprehensible sounds such as grunting. 
in $48.54 \%$. Figure 2 is a clinical example of an 11 years old boy who sustained a moderate TBI with a massive depressed skull fracture with sagittal and lambdoid sutures dislocation.

\subsection{Radiological Data}

All patients but one had a brain CT scan (99\%), five, a skull and two a cervical spine X-ray. Table 3 shows the lesions found on CT. The most radiological finding was post-traumatic cerebral edema.

\subsection{Management Data}

The management (Table 3 ) has consisted in medical treatment in all cases and surgery in 28. Paracetamol was administered to all but one patients (99\%), $3^{\text {rd }}$ generation cephalosporin (mainly ceftriaxone) to 83 (80.60\%), and Mannitol infusion to $52(50.50 \%)$.

\subsection{Outcome Data}

The overall mortality was $3.88 \%$ with 4 deaths. Ninety-three $(90.28 \%)$ patients recovered fully and six $(5.82 \%)$ had mild to moderate disability. The persisting

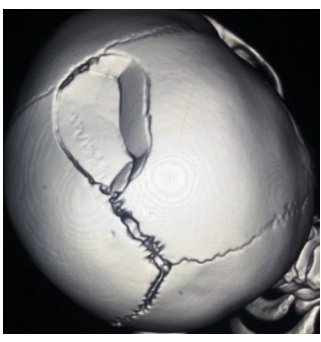

(a)

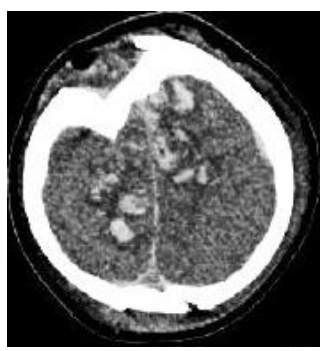

(d)

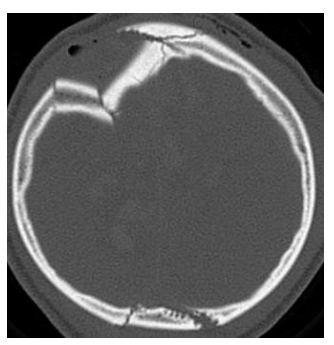

(b)

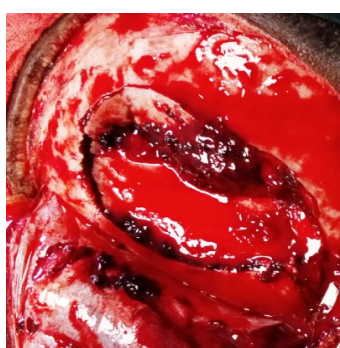

(e)

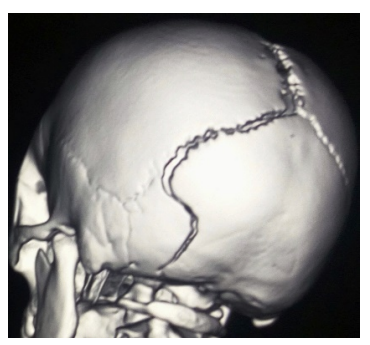

(c)

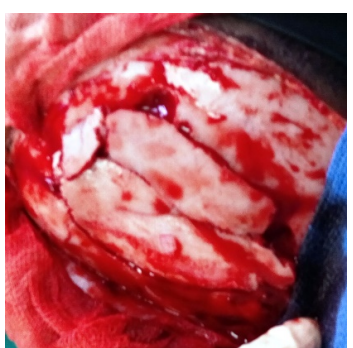

(f)

Figure 2. Clinical case of depressed skull fracture. This 11 years-old boy was struck on the head by a falling object. He presented at the emergency department with agitation, consciousness disturbance with left side hemiplegia. The admission Glasgow coma scale (GCS) score was 11. The computed tomography scanning of the head showed a right anterior parietal parasagittal depressed skull fracture crossing the midline ((a), (b)) with dislocation of the posterior half of the sagittal suture and the left part of the lambdoid suture (c); Multiple brain contusion were present under the depressed bone fragments (d); Intraoperative view of the depressed skull fracture before (e) and after elevation of bone fragments (f). The postoperative course was unremarkable. The GCS score returned to 15 three days after surgery and the left hemiplegia was regressing by the time the child was discharged from hospital at day 7 post-surgery. 
Table 3. Profile of children with TBI.

\begin{tabular}{|c|c|c|}
\hline Variable & Number & Percent (\%) \\
\hline \multicolumn{3}{|l|}{ Mode of injury } \\
\hline Road traffic accident & 46 & 44.66 \\
\hline Fall & 42 & 40.77 \\
\hline Assault & 07 & 06.80 \\
\hline Domestic accident & 04 & 03.88 \\
\hline Sport accident & 04 & 03.88 \\
\hline \multicolumn{3}{|l|}{ Transportation means } \\
\hline Medical ambulance & 10 & 09.71 \\
\hline Non-medical vehicle & 93 & 90.29 \\
\hline \multicolumn{3}{|l|}{ Admission GCS score } \\
\hline 13 - 15 (mild TBI) & 63 & 61.16 \\
\hline 09 - 12 (moderate TBI) & 34 & 33.01 \\
\hline$\leq 8($ severe $\mathrm{TBI})$ & 06 & 05.82 \\
\hline \multicolumn{3}{|l|}{ Clinical manifestations } \\
\hline Loss of consciousness & 50 & 48.54 \\
\hline Scalp wound & 43 & 41.74 \\
\hline Periorbital ecchymosis & 40 & 38.83 \\
\hline Vomiting & 38 & 36.89 \\
\hline Headache & 31 & 30.09 \\
\hline Seizures & 28 & 27.18 \\
\hline \multicolumn{3}{|l|}{ Time interval ${ }^{*}$} \\
\hline $0-24$ hours & 49 & 47.57 \\
\hline $24-48$ hours & 05 & 04.06 \\
\hline$>48$ hours & 49 & 47.57 \\
\hline \multicolumn{3}{|l|}{ Computed tomography findings } \\
\hline Cerebral edema & 37 & 35.92 \\
\hline Skull fracture (depressed) & $35(15)$ & $33.98(14.56)$ \\
\hline Acute subdural hematoma & 19 & 18.44 \\
\hline Intra cerebral hematoma & 10 & 09.71 \\
\hline Epidural hematoma & 08 & 07.77 \\
\hline Subarachnoid hemorrhage & 02 & 01.94 \\
\hline \multicolumn{3}{|l|}{ Management } \\
\hline Analgesics & 102 & 99.03 \\
\hline Antibiotics & 83 & 80.58 \\
\hline Mannitol & 52 & 50.48 \\
\hline Antiepileptic & 22 & 21.36 \\
\hline Oxygen therapy & 13 & 12.62 \\
\hline Blood transfusion & 07 & 06.79 \\
\hline Craniotomy ${ }^{\S}$ & 22 & 21.36 \\
\hline Scalp wound suture & 06 & 05.82 \\
\hline \multicolumn{3}{|l|}{ Outcome } \\
\hline Full recovery & 93 & 90.29 \\
\hline Persisting symptoms ${ }^{\#}$ & 06 & 05.82 \\
\hline Death & 04 & 03.88 \\
\hline
\end{tabular}

GCS: Glasgow coma scale. ${ }^{\star}$ : time interval between trauma and admission. ${ }^{\varsigma}$ : for removal of intracranial hematomas or depressed skull fractures. ${ }^{*}$ : hemiparesis, one case; chronic headaches, five cases. TBI: traumatic brain injury. 
disability consisted in hemiparesis in one case and chronic headaches in four. It is only the GCS score at admission which significantly influenced the outcome (Table 4). The time interval between trauma and arrival at the hospital, gender, age, and the treatment modality did not have an impact on the outcome.

\section{Discussion}

Most findings from this series such as age, gender, cause of trauma, were consistent with data from the literature [1] [3] [4] [5]. The prevalence for pediatric TBI amongst all cases of TBI was $10.43 \%$ in this series. This frequency varies depending on the population studied [17] [18].

Table 4. Prognostic factors.

\begin{tabular}{|c|c|c|c|c|c|c|}
\hline $\begin{array}{l}\text { Relation between } \\
\text { time interval \& } \\
\text { admission GCS }\end{array}$ & $\begin{array}{l}\text { Mild to } \\
\text { moderate TBI } \\
\text { (GCS } 9 \text { to } 15)\end{array}$ & $\begin{array}{c}\text { Severe TBI } \\
(\mathrm{GCS} \leq 8)\end{array}$ & Total & Chi-square & DDL & $P$ value \\
\hline Delay $<24 \mathrm{~h}$ & 46 & 3 & 49 & & & \\
\hline Delay $>24 \mathrm{~h}$ & 51 & 3 & 54 & 0.167 & 1 & $0.683(\mathrm{NS})$ \\
\hline Total & 97 & 6 & 103 & & & \\
\hline \multicolumn{7}{|l|}{ Outcome \& the GCS } \\
\hline Full recovery & 90 & 3 & 93 & \multirow{5}{*}{14.96} & \multirow{5}{*}{1} & \multirow{5}{*}{0.001} \\
\hline Disability $^{*}$ & 05 & 1 & 06 & & & \\
\hline Death & 02 & 2 & 04 & & & \\
\hline Total & 97 & 6 & 103 & & & \\
\hline Outcome \& gender & Survivors & Deceased & Total & & & \\
\hline Boys & 72 & 3 & 75 & \multirow{3}{*}{0.01} & \multirow{3}{*}{1} & \multirow{3}{*}{$0.92(\mathrm{NS})$} \\
\hline Girls & 27 & 1 & 28 & & & \\
\hline Total & 99 & 4 & 103 & & & \\
\hline Outcome \& age & Survivors & Deceased & Total & \multirow{7}{*}{1.92} & \multirow{7}{*}{3} & \multirow{7}{*}{0.955 (NS) } \\
\hline $0-2$ & 21 & 0 & 21 & & & \\
\hline $3-5$ & 25 & 2 & 27 & & & \\
\hline $6-10$ & 19 & 1 & 20 & & & \\
\hline $11-15$ & 34 & 1 & 35 & & & \\
\hline Total & 99 & 4 & 103 & & & \\
\hline Outcome \& treatment & Survivors & Deceased & Total & & & \\
\hline Non-operated & 72 & 3 & 75 & \multirow{3}{*}{0.003} & \multirow{3}{*}{1} & \multirow{3}{*}{0.955 (NS) } \\
\hline Operated & 22 & 1 & 28 & & & \\
\hline Total & 99 & 4 & 103 & & & \\
\hline
\end{tabular}

GCS: Glasgow coma scale, TBI: traumatic brain injury, h: hour, NS: non-significant. * : one hemiparesis \& five chronic headaches. The only significant prognostic factor was the GCS at admission. The mortality for mild and moderate TBI was $2.06 \%$ (2 deaths out of 97 children), while that of severe TBI was $33.33 \%$ ( 2 deaths out of 6 patients); the prevalence of persisting disability was $5.26 \%$ in the survivors with mild and moderate TBI (5/95), and $25 \%$ in survivors with severe TBI (1/4). Time interval between trauma \& admission, gender, age, and treatment modality had no impact on the outcome. 


\subsection{Age Distribution}

The age distribution of children who sustained TBI varies amongst series. In the present series, children aged between 0 and 5 years were the most involved, followed by those between 11 and 15 years of age. This finding is similar to data reported by other authors [1] [4] [7] [17] [18].

\subsection{Gender}

The male predominance for TBI even in children is unanimously reported from the literature suggesting that males and hence boys, are more exposed to activities at risk for TBI [1] [6] [7] [10] [12] [13] [14] [17] [18]. In the present series, boys represented $73 \%$ of children who sustained a TBI.

\subsection{The Cause of TBI}

The falls are the $1^{\text {st }}$ mode of injury for pediatric TBI, mainly before six years of age, followed by road traffic accidents [1] [6] [10] [12] [17] [18]. In this series, the RTA was the first mechanism of injury accounting for $44.7 \%$ of PTBI and falls were second with $40.8 \%$. The motorcycles were involved in most of the RTA because motorcycles are the main mean of transport in the Douala city area.

\subsection{Clinical Aspect}

Most TBI are mild both in children and adults. This is consistent with findings from this series in which $61.20 \%$ of PTBI were mild (GCS 13 to 15 ). The predominance of mild and moderate TBI in children can be explain by many factors: in children up to two years of age, the skull is deformable and can absorb shock better than adult skull; most accidents occur at home and are therefore low-energy injuries; parents may be more worried even in cases of light blow and may be more prone to bring children to the hospital [16].

Concerning the clinical findings, the initial loss of consciousness was the most common symptom observed in $50(48.50 \%)$ children, and this finding was consistent with reported data [12] [13] [14]. Vomiting was observed in $36.90 \%$ of cases from this series. Vomiting is frequent in pediatric TBI but, in the presence of consciousness alteration, it can cause inhalation and lead to inhalation pneumonia which can worsen the prognosis. Seizures' frequency $(27.20 \%)$ in this series was higher compared to data from other authors. Headaches are common in TBI and can persist long after the injury and spoil the child life. Its frequency varies from $9 \%$ to $72 \%$ according to [5] [18] [19]. Headaches were found in 31 (30.10\%) of our children and four of them were disabled by chronic persisting headaches. The scalp wounds are also frequent in TBI. They can range from pin-point wound to huge scalp avulsions. Their frequency varies amongst series. Forty-three (41.70\%) children of this series had a wound of the scalp. The time interval between the TBI and admission at the emergency department of GHD was more than 48 hours in $47.6 \%$ (48) of the cases. This reflects the fact that the General Hospital, Douala is a tertiary referral health institution and therefore, 
children were transported primarily to other health facilities. This was corroborated by the fact that $83.5 \%$ of children of this series were referred to GHD in second intention. But, this did not have a significant impact on the outcome.

\subsection{CT Scan Findings}

The CT scanning of the head is the imaging tool of $1^{\text {st }}$ intention for patients with TBI [5] [10] [12] [13] [14]. The CT scanning of the head was done in $99 \%$ $(102 / 103)$ of the cases in this series. The most common findings were cerebral edema, linear and depressed skull fractures, and the acute subdural hematomas.

\subsection{Management}

In this series, 22 patients (21.36\%) needed a craniotomy for intracranial hematomas or depressed skull fractures and six had sutured scalp wounds. Therefore, the prevalence for post-traumatic intracranial lesions requiring surgery was $13.59 \%$ (14 children). In the series from O'Lynnger et al. 20 to 32\% of children with severe TBI needed a neurosurgical operation [11]. In 2009, Kuppermann et al. [20] have found that, for 42,412 children admitted in hospitals in the USA, $0.9 \%$ had significant post-traumatic intracranial lesions and only $0.1 \%$ were operated. This discrepancy with our results can be explained by a selection bias from our series since its study population was withdrawn from head trauma patients and not from global pediatric admissions.

\subsection{Outcome}

TBI can be detrimental on a developing brain with a negative impact on school performance and family functioning with a high economic cost, and this is particularly true for severe TBI in which mortality can reach $20 \%$ with $50 \%$ unfavorable outcome at six-month [6]. Long-term neurocognitive assessment of children who sustained a TBI has shown cognitive, emotional and behavioral impairment in a significant number [5] [8] [9] [15] [16] [21]. Nevertheless, most children who have sustained a TBI will recover fully (Table 4). This was consistent with this series where $90.28 \%$ of children recovered fully. One child was moderated disabled (hemiparesis) and four complained of chronic headaches. The mortality was also low and consistent with data from the literature [1] [6] [8] [9] [10] [15] [16] [19] [21]. Age, gender, treatment modality (surgery or not), and time interval between trauma and admission to the hospital did not influence the outcome, but the admission GCS score (trauma severity) did. In the present series, the mortality and persisting disabilities were significantly higher in children with severe TBI than those with mild or moderate TBI. The mortality for mild and moderate TBI was $2.06 \%$ (2 deaths out of 97 children), while that of severe TBI was 33.33\% (2 deaths out of 6 patients); the prevalence of persisting disability was $5.26 \%$ in the survivors with mild and moderate TBI (5/95), and $25 \%$ in survivors with severe TBI $(1 / 4)$, $\mathrm{p}$ value $=0.001$. But it is established that the time elapsed from trauma to treatment favors secondary brain insults and influence the outcome, but this was not the case in this pediatric series. The 
good prognosis in this series can also be explain by the high proportion of mild and moderate PTBI $(97 ; 94.17 \%)$ compared to severe ones $(6 ; 05.82 \%)$.

\section{Conclusion}

In conclusion, the frequency of pediatric TBI amongst patients admitted for TBI at the General Hospital, Douala, Cameroon for the last ten years was $10.43 \%$. The pediatric TBI was more frequent in boys than in girls and affected most often early childhood and pre-adolescent children. The road traffic accident was the first mode of injury and implicated motorcycles most of the time, and falls were second after RTA. Most of the patients were transferred at the GHD in second intention by non-medical transport. Almost two-third of pediatric TBI was mild and the loss of consciousness was the most frequent symptom. The CT scan of the head was systematically done and it has revealed most often post-traumatic cerebral edema. The mortality was low and full recovery was the rule. The main limitation of the study was its retrospective aspect. For that reason, some medical files had incomplete data and we could analyze only data which were gathered.

\section{Acknowledgements}

We thank Miss NDIMBA Erica for her help with the corrections.

\section{Conflicts of Interest}

None.

\section{References}

[1] Bruns Jr., J. and Hauser, W.A. (2003) The Epidemiology of Traumatic Brain Injury: A Review. Epilepsy, 44, 2-10. https://doi.org/10.1046/j.1528-1157.44.s10.3.x

[2] Carroll, L.J., Cassidy, J.D., Holm, L., Kraus, J. and Coronado, V.G. (2004) Methodological Issues and Recommendations for Mild Traumatic Brain Injury: The WHO Collaborating Center Task Force on Mild Traumatic Brain Injury. Journal of Rehabilitation Medicine, 43, 113-125. https://doi.org/10.1080/16501960410023877

[3] Chan, V., Thurairajah, P. and Colantino, A. (2015) Defining Pediatric Traumatic Brain Injury Using International Classification of Diseases Version 10 Codes: A Systematic Review. BMC Neurology, 15, 7. https://doi.org/10.1186/s12883-015-0259-7

[4] Patel, M., Janich, K., Doan, H., Nguyen, H.S., Shabani, S. and Doan, N. (2016) Management of Pediatric Traumatic Brain Injury: A Mini Review. International Journal of Physical Medicine \& Rehabilitation, 4, 6. https://doi.org/10.4172/2329-9096.1000378

[5] Kirkwood, M.W., Yeates, K.O., Taylor, H.G., Randolph, C., McCrea, M. and Anderson, V.A. (2008) Management of Pediatric Mild Traumatic Brain Injury: A Neuropsychological Review from Injury through Recovery. The Clinical Neuropsychologist, 22, 769-800. https://doi.org/10.1080/13854040701543700

[6] Murtaugh, B. (2013) Brain Injury Medicine.

[7] Araki, T., Yokota, H. and Morita, A. (2017) Pediatric Traumatic Brain Injury: Cha- 
racteristic Features, Diagnosis, and Management. Neurologia Medico-Chirurgica, (Tokyo), 57, 82-93. https://doi.org/10.2176/nmc.ra.2016-0191

[8] Giza, C.C. (2006) Lasting Effects of Pediatric Traumatic Brain Injury. Indian Journal of Neurotrauma (IJNT), 3, 19-26. https://doi.org/10.1016/S0973-0508(06)80005-5

[9] Königs, M., Heij, H.A., van der Sluijs, J.A., Vermeulen, R.J., Goslings, J.C., Luitse, J.S.K., Poll-Thé, B.T., Beelen, A., van der Wees, M., Kemps, R.J.J.K., Catsman-Berrevoets, C.E. and Oosterlaan, J. (2015) Pediatric Traumatic Brain Injury and Attention Deficit. Pediatrics, 136, 534-541. https://doi.org/10.1542/peds.2015-0437

[10] Greenberg, M.S. (2001) Pediatric Head Injury. In: Handbook of Neurosurgery, 5th Ed., Thieme Medical Publishers, New York, 677-679.

[11] O’Lynnger, T.M., Shannon, C.N., Le, T.M., Greeno, A., Chung, D., Lamb, F.S. and Wellons, J.C. (2016) Standardizing ICU Management of Pediatric Traumatic Brain Injury Is Associated with Improved Outcomes at Discharge. Journal of Neurosurgery Pediatrics, 17, 19-26. http://thejns.org/doi/abs/10.3171/2015.5.PEDS1544 https://doi.org/10.3171/2015.5.PEDS1544

[12] Ndoumbé, A., Ngoyong Edu, P.B., Simeu, C. and Takongmo, S. (2018) Epidemiological Analysis of 135 Cases of Severe Traumatic Brain Injury Managed at a Surgical Intensive Care Unit. Open Journal of Modern Neurosurgery, 8, 119-131. https://doi.org/10.4236/ojmn.2018.81010

[13] Ndoumbé, A., Ekeme, M.V.P., Simeu, C. and Takongmo, S. (2018) Outcome of Surgically Treated Acute Traumatic Epidural Hematomas Based on the Glasgow Coma Scale. Open Journal of Modern Neurosurgery, 8, 109-118. https://doi.org/10.4236/ojmn.2018.81009

[14] Ndoumbé, A., Ekeme, M.V.P., Jemea, B., Simeu, C. and Takongmo, S. (2016) Epidemiological Analysis of Surgically Treated Acute Traumatic Epidural Hematoma. Open Journal of Modern Neurosurgery, 6, 89-97. https://doi.org/10.4236/ojmn.2016.63016

[15] Jagannathan, J., Okonkwo, D.O., Yeoh, H.K., Dumont, A.S., Saulle, D., Haizlip, J., Barth, J.T., Jane Sr, J.A. and Jane Jr, J.A. (2008). Long-Term Outcomes and Prognostic Factors in Pediatric Patients with Severe Traumatic Brain Injury and Elevated Intracranial Pressure. Journal of Neurosurgery Pediatrics, 2, 240-224. https://doi.org/10.3171/PED.2008.2.10.240

[16] Rashid, M., Goez, H.R., Mabood, N., Damanhoury, S., Yagera, J.Y., Joyce, A.S. and Newton, A.S. (2014) The Impact of Pediatric Traumatic Brain Injury (TBI) on Family Functioning: A Systematic Review. Journal of Pediatric Rehabilitation Medicine: An Interdisciplinary Approach, 7, 241-253.

[17] Knobel, G.J., De Villiers, J.C., Parry, C.D.H. and Botha, J.L. (1984) The Causes of Non-Natural Deaths in Children over a 15-Year Period in Greater Cape Town. South African Medical Journal, 66, 795-801.

[18] Lalloo, R. and van As, A.B. (2004) Profile of Children with Head Injuries Treated at the Trauma Unit of Red Cross War Memorial Children's Hospital, 1991-2001. South African Medical Journal, 94, 544-546.

[19] Kuezynski, A., Crawford, S. and Bodell, L. (2003) Characteristics of Post-Traumatic Headaches in Children Following Mild Traumatic Brain Injury and Their Response to Treatment: A Prospective Cohort. Developmental Medicine \& Child Neurology, 55, 636-641. https://doi.org/10.1111/dmcn.12152

[20] Kuppermann, N., Holmes, J.F. and Dayan, P.S. (2009) Identification of Children at 
Very Low Risk of Clinically-Important Brain Injuries after Head Trauma: Prospective Cohort Study. The Lancet, 374, 1160-1170.

https://doi.org/10.1016/S0140-6736(09)61558-0

[21] Zuccarello, M., Facco, E., Zampieri, P., et al. (1985) Severe Head Injury in Children: Early Prognosis and Outcome. Child s Nervous System, 1, 158-162.

https://doi.org/10.1007/BF00735731

\section{Abbreviations Used in This Article}

CT: Computed Tomography. PTBI: Pediatric Traumatic Brain Injury. TBI: Traumatic Brain Injury. EDH: Epidural or Extradural Hematoma. GCS: Glasgow Coma Scale. GHD: General Hospital, Douala. ICU: Intensive Care Unit. LOC: Loss of Consciousness. SAH: Subarachnoid Hemorrhage. WHO: World Health Organization. 